Check for updates

Cite this: RSC Adv., 2017, 7, 54407

Received 25th August 2017

Accepted 1st November 2017

DOI: $10.1039 / c 7 r a 09414 k$

rsc.li/rsc-advances

\section{A pharmaceutical hydrogen-bonded covalent organic polymer for enrichment of volatile iodine $\uparrow$}

\author{
Lin Lin, ${ }^{a}$ Heda Guan, ${ }^{a}$ Donglei Zou, ${ }^{a}$ Zhaojun Dong, ${ }^{a}$ Zhi Liu, ${ }^{b}$ Feifan Xu, ${ }^{a}$ Zhigang Xie ${ }^{c}$ \\ and Yangxue Li (D) *a
}

Porous organic polymers (POPs) are emerging porous materials for various applications. So far, POPs are currently synthesised by a few limited synthetic chemical reactions, leading to a lack of new structures and properties. Thus, expanding structural diversity is highly desired for the development of this promising class of porous materials. Herein, adopting pharmaceutical isoniazid as a difunctional linker, a pharmaceutical hydrogen-bonded covalent organic polymer (pha- $\mathrm{H}_{\mathrm{C}} \mathrm{OP}-1$ ) has been synthesised for iodine enrichment. The structure and morphology are studied by TGA, FT-IR, FE-SEM, HR-TEM and ${ }^{13} \mathrm{C}$ CP/MAS NMR. Powder $\mathrm{X}$-ray diffraction and $\mathrm{N}_{2}$ adsorption-desorption analysis show that pha- $\mathrm{H}_{\mathrm{C}} \mathrm{OP}-1$ is amorphous and porous with a surface area of $217.31 \mathrm{~m}^{2} \mathrm{~g}^{-1}$. The pha- $\mathrm{H}_{\mathrm{C}} \mathrm{OPs}$ are spherical particles with an average size of $20 \mathrm{~nm}$. Due to the abundant porosity, $\pi$-conjugated phenyl rings, as well as functional - $\mathrm{CO}-\mathrm{NH}$ - building units, pha- $\mathrm{H}_{\mathrm{C}} \mathrm{OP}-1$ exhibits a good adsorption ability for iodine molecules. The pha$\mathrm{H}_{\mathrm{C}} \mathrm{OP}-1$ has a high uptake value of $131 \mathrm{wt} \%$ via vapor trapping adsorption. Meanwhile, pha- $\mathrm{H}_{\mathrm{C}} \mathrm{OP}-1$ also exhibits an outstanding iodine adsorption in solution, and the maximum adsorption capacity reaches as high as $833.33 \mathrm{mg} \mathrm{g}^{-1}$ analyzed using a Langmuir model. In addition, the thermodynamic parameters $\Delta G, \Delta H$ and $\Delta S$ indicate that the adsorption of iodine by pha- $\mathrm{H}_{C} \mathrm{OP}-1$ is feasible, spontaneous and endothermic. pha- $\mathrm{H}_{\mathrm{C}} \mathrm{OP}-1$ represents an elegant example of using pharmaceutical molecules as building blocks to construct porous POPs for reversible adsorption of radioactive iodine.

\section{Introduction}

Porous organic polymers (POPs), as the organic analogues of zeolites and metal-organic frameworks (MOFs), have become a rising star in the field of porous materials during the last few years by virtue of their large surface area along with facile synthesis and low skeleton density. ${ }^{1-9}$ To name a few, crystalline covalent organic frameworks (COFs) by Yaghi, ${ }^{10}$ covalent triazine-based frameworks (CTFs) by Antonietti and Thomas, ${ }^{\mathbf{1 1}}$ hyper-cross-linked polymers (HCPs), ${ }^{12}$ amorphous conjugated microporous polymers $(\mathrm{CMPs})^{13}$ by Cooper, polymers of intrinsic microporosity (PIMs) by Budd and McKeown, ${ }^{\mathbf{1 4}}$ and porous aromatic frameworks (PAFs) by $\mathrm{Zhu}$ and $\mathrm{Qiu}^{15}$ have shown their outstanding properties and functions in gas storage and separation, catalysis, sensing and electronics. ${ }^{\mathbf{1 6 - 3 0}}$ Generally, POPs are constructed from two monomer units

${ }^{a}$ Key Lab of Groundwater Resources and Environment, Ministry of Education, Jilin University, 2519 Jiefangda Road, Changchun 130021, P. R. China. E-mail: yangxueli@jlu.edu.cn

${ }^{b}$ Changchun Institute of Urban Planning and Design, Changchun 13000, P. R. China ${ }^{c}$ State Key Laboratory of Polymer Physics and Chemistry, Changchun Institute of Applied Chemistry, Chinese Academy of Sciences, 5625 Renmin Street, Changchun 130022, P. R. China

$\dagger$ Electronic supplementary information (ESI) available: Characterization figure and supporting figures. See DOI: 10.1039/c7ra09414k through one type of coupling or condensation reaction, such as Sonogashira-Hagihara coupling, Yamamoto coupling, Suzuki coupling, alkyne-alkyne homo-coupling, imine condensation reactions, amide condensation reactions, boroxine ring condensation reactions and so on. ${ }^{31,32}$ However, compared to MOFs, the structural heterogeneity and functional diversity of POPs are quite restricted because of the finite synthetic chemical reactions and monotonous building blocks. Thus, it is a crucial and emergent task to avoid such limitations and allow multiple linkages for the construction of POPs.

Inspired by the heterostructural mixed linker approach, which is commonly used in MOF, designing crystalline COFs with mixing blocks could create novel topologies and improve structural heterogeneity. ${ }^{33}$ For example, Jiang's group adopted a double-stage synthesis technique to construct new type of COFs with enhanced structural complexity and diversity, and Zhao's group developed COFs by reversible formations of two types of covalent bonds, respectively. ${ }^{34,35}$ Similarly, explorating amorphous POP materials with multiple linkages and various different multi-functional components might also be a powerful tool to advance the research progress of this class of porous materials.

With the increasing energy demand and environmental deterioration in the world nowadays, nuclear energy is becoming more and more popular because of its high energy 
density and no pollutant emission. ${ }^{36,37}$ During the normal operation of nuclear power plants, the radioactive waste would be generated from the nuclear fission of uranium. ${ }^{38,39}$ Among these radionuclides including ${ }^{129} \mathrm{I}$ and ${ }^{131} \mathrm{I},{ }^{3} \mathrm{H},{ }^{14} \mathrm{CO}_{2}$, and ${ }^{85} \mathrm{Kr}$, the radiological iodine attracts particular attention because of the long-lived isotope of ${ }^{129} \mathrm{I}$ (half-life of $1.57 \times 10^{7}$ years) and the involvement in human metabolic processes of ${ }^{131} \mathrm{I}^{40-42}$ In particular, the nuclear accident at Fukushima, Japan in 2011 has raised understanding of the urgent need for radiation protection and awareness of proper nuclear waste management. Hence, taking effective measures to control radioactive iodine pollution becomes a pressing problem in the field of environment.

In view of the specific activity and high volatile characteristic of the radioactive iodine, it is highly desired to develop effective methods for capture and storage of radioactive. Many methods have been reported on the treatment of radioactive $I_{2}$. Adsorption, ion exchange, membrane separation, evaporation recovery, electrolysis and chemical precipitation are well-known processes to trap the radioactive iodine..$^{42}$ Notably, among the methods mentioned above, adsorption has been proven to be a simple, clean, low cost and high-efficient method. So far, a variety of absorbents have been used for effective enrichment of radiological iodine, such as inorganic porous materials, metal-organic frameworks (MOFs) and porous organic polymers (POPs), etc. ${ }^{43-46}$ Among these absorbents, because of the intrinsic porous architectures and the devisable adsorption sites for iodine, the exploration of POPs in the capture of iodine is in full swing. Just recently, Zhu's and Deng's groups reported charged PAFs and CMP nanotubes used for efficient volatile iodine capture and storage, respectively. ${ }^{47,48}$ Despite the impressive progress in this area, it is still desirable to develop other novel improved materials for addressing iodine absorption.

Herein, starting from pharmaceutical isoniazid, a porous hydrogen-bonded covalent organic polymer (pha- $\mathrm{H}_{\mathrm{C}} \mathrm{OP}-1$ ) was designed and synthesized for iodine enrichment. The new material design relies on both the functionalization and structural chemistry: (1) incorporating monomers containing -CONH- functionality as material building blocks to enhance the binding affinity between the adsorbent and iodine molecules. $^{\mathbf{4 9 5 0}}$ (2) $\mathrm{H}_{\mathrm{C}} \mathrm{OPs}$ constructed by two types of linkages and three different components, could expand structural diversity and complexity, thus providing a new phase for structural design and functional exploration. ${ }^{51-53}$ We have studied that pha- $\mathrm{H}_{\mathrm{C}} \mathrm{OP}-1$ served as a host framework for iodine enrichment. Additionally, as far as we know, the iodine adsorption and storage properties of pharmaceutical $\mathrm{H}_{\mathrm{C}} \mathrm{OPs}$ is rare.

\section{Experimental}

\section{Materials and measurements}

All starting materials were purchased from commercial suppliers and used without further purification unless otherwise noted. Solvents were purified according to standard procedures. Trimethyl benzene-1,3,5-tricarboxylate, benzene1,3,5-tricarbohydrazide and reference compound of INH-BA (isoniazid-benzaldehyde) were synthesized according to the reported literature. ${ }^{54-56}$ The thermogravimetric analysis (TGA) was performed using a NetzchSta 449c thermal analyzer system at the heating rate of $10{ }^{\circ} \mathrm{C} \mathrm{m^{-1 }}$ in air atmosphere. Elemental analyses were measured by Elementar model Vario Micro analyzer. The Fourier transform infrared spectrometer (FT-IR) spectra were measured using a Nicolet Impact 410 Fourier transform infrared spectrometer. The nitrogen adsorption isotherm was measured on an Autosorb iQ2 adsorptometer, Quantachrome Instruments. The powder X-ray diffraction (PXRD) was performed by a Riguku D/MAX2550 diffractometer using $\mathrm{CuK} \alpha$ radiation, $40 \mathrm{kV}, 200 \mathrm{~mA}$ with scanning rate of $4^{\circ} \mathrm{min}^{-1}$. Transmission electron microscopies (TEM) and high resolution transmission electron microscopies (HR-TEM) were recorded using a FEI Tecnai G2F20 s-twin D573 with an acceleration voltage of $300 \mathrm{kV}$. The TEM samples were prepared by drop-casting a supersonicated dichloromethane suspension of pha- $\mathrm{H}_{\mathrm{C}} \mathrm{OPs}$ onto a copper grid. Field-scanning electron microscopies (FE-SEM) were performing on JEOLJXA-840 under an accelerating voltage of $15 \mathrm{kV}$. The FE-SEM samples were prepared by adhering pha- $\mathrm{H}_{\mathrm{C}} \mathrm{OP}-1$ powders to mica substrate using conductive tape and then coating with gold. The ${ }^{1} \mathrm{H}-\mathrm{NMR}$ spectra were recorded at $400 \mathrm{MHz}$ in $\mathrm{DMSO}^{-\mathrm{d}_{6}}$ as internal standard with TMS, and the solid-state ${ }^{13} \mathrm{C}$ cross polarization/magic angle spinning nuclear magnetic resonance (CP/MAS NMR) spectrum was recorded at $5 \mathrm{kHz}$. The X-ray photoelectron spectroscopy (XPS) was recorded on a ESCALAB 250Xi X-ray photoelectron spectroscopy.

\section{Synthesis of trimethyl benzene-1,3,5-tricarboxylate}

Benzene-1,3,5-tricarboxylic acid (2 g) was added into $200 \mathrm{~mL}$ $\mathrm{CH}_{3} \mathrm{OH}$, then $\mathrm{TsOH}(100 \mathrm{mg})$ was added in, then the mixture was heated to reflux for $48 \mathrm{~h}$ under $\mathrm{N}_{2}$ atmosphere. Next, the reaction was quenched with a saturated aqueous $\mathrm{NaHCO}_{3}$ solution and the resulting mixture was extracted with diethyl ether. The organic layer was washed with water and brine, then dried over $\mathrm{Na}_{2} \mathrm{SO}_{4}$. The solvent were evaporated in vacuo, yielding trimethyl benzene-1,3,5-tricarboxylate $(2 \mathrm{~g})$ as a white powder. ${ }^{1} \mathrm{H}$ NMR (400 MHz, $\left.\mathrm{CDCl}_{3}\right) \delta 8.86(\mathrm{~d}, J=1.5 \mathrm{~Hz}, 1 \mathrm{H})$, $3.98(\mathrm{~s}, 3 \mathrm{H})$.

\section{Synthesis of benzene-1,3,5-tricarbohydrazide}

Hydrazine monohydrate $(5 \mathrm{~mL})$ was added in portions to a solution of trimethyl benzene-1,3,5-tricarboxylate (1 g) in methanol. The mixture was stirred for $48 \mathrm{~h}$ under reflux, yielding white slurry. Then filtered and washed with methanol, yielding benzene-1,3,5-tricarbohydrazide as a white powder. ${ }^{1} \mathrm{H}$ NMR (400 MHz, DMSO-d 6 ) $\delta 9.83$ (s, 1H), 8.32 (s, 1H), 4.58 (s, $2 \mathrm{H})$.

\section{Synthesis of pha- $\mathrm{H}_{\mathrm{C}} \mathrm{OP}-1$}

Into a $20 \mathrm{~mL}$ glass vial was added benzene-1,3,5tricarbohydrazide (BTCH, $0.2 \mathrm{mmol}, 0.05 \mathrm{~g}$ ), isoniazid (INH, $0.3 \mathrm{mmol}, 0.042 \mathrm{~g}$ ), terephthalaldehyde (TPA, $0.3 \mathrm{mmol}, 0.04 \mathrm{~g}$ ), $\mathrm{CF}_{3} \mathrm{COOH}$ (TFA, $2 \mathrm{~d}$ ) and a solution of dimethyl sulphoxide (DMSO, $10 \mathrm{~mL}$ ). The reaction mixture was heated at $100{ }^{\circ} \mathrm{C}$ for 
$1 \mathrm{~h}$ to afford a yellow precipitate and washed with various organic solvents, such as methanol and acetone, to afford pharmaceutical hydrogen-bonded covalent organic polymer 1 (pha- $\mathrm{H}_{\mathrm{C}} \mathrm{OP}-1$ ) in $85 \%$ yields. Elemental analysis (wt\%) calcd for $\left\{\mathrm{C}_{32} \mathrm{H}_{40} \mathrm{~N}_{9} \mathrm{O}_{4}\right\}_{n}$ : C 62.52, H 6.56, N 20.51; found: $\mathrm{C} 60.55, \mathrm{H}$ 6.16, N 21.44.

\section{Uptake of iodine}

The solid iodine adsorption experiments were performed in the following manner. First, the pha- $\mathrm{H}_{\mathrm{C}} \mathrm{OP}$ samples were placed into a sealed vessel, which filled with nonradioactive iodine vapor at $353 \mathrm{~K}$ and atmospheric pressure. Then, gravimetric method was conducted to determine the iodine uptake of pha$\mathrm{H}_{\mathrm{C}}$ OPs at various time intervals. The uptake of iodine for pha$\mathrm{H}_{\mathrm{C}} \mathrm{OPs}$ samples were calculated according to the formula:

$$
\alpha=\frac{m_{2}-m_{1}}{m_{1}} \times 100 \%
$$

where $\alpha$ is the iodine uptake, $m_{1}$ and $m_{2}$ are the quality of pha$\mathrm{H}_{\mathrm{C}} \mathrm{OPs}$ before and after iodine uptake.

To examine the adsorption capacity of iodine in hexane, the pha- $\mathrm{H}_{\mathrm{C}} \mathrm{OPs}(10 \mathrm{mg})$ were immersed in the iodine/hexane solution (100-1000 $\mathrm{mg} \mathrm{L}^{-1}, 10 \mathrm{~mL}$ ) and kept for a period of time. Then the absorbency of supernatant was measured by using UVvis at various time intervals.

The removal efficiency $(E, \%)$ and the amount of iodine adsorbed $q_{\mathrm{e}}\left(\mathrm{mg} \mathrm{g}^{-1}\right)$ were given according to the formula:

$$
\begin{aligned}
q_{\mathrm{e}} & =\frac{\left(C_{0}-C_{\mathrm{e}}\right) V}{m} \\
E(\%) & =\frac{C_{0}-C_{\mathrm{e}}}{C_{0}} \times 100 \%
\end{aligned}
$$

where $C_{0}\left(\mathrm{mg} \mathrm{L}^{-1}\right)$ is the initial concentration of iodine in the solution, and $C_{\mathrm{e}}\left(\mathrm{mg} \mathrm{L}^{-1}\right)$ is the equilibrium concentration of iodine in the solution, respectively; $m$ is the mass of adsorbent used (g); $V$ is the volume of solution used (L).

\section{Release of iodine}

The samples with iodine uptake (named as $\mathrm{I}_{2}$ @pha- $\mathrm{H}_{\mathrm{C}} \mathrm{OP}-1$, $10 \mathrm{mg}$ ) were immersed in the methanol solution $(10 \mathrm{~mL})$ and kept for a certain time. Then the absorbency of supernatant was measured by using UV-vis at various time intervals.

\section{Results and discussion}

\section{Physicochemical characterization of the adsorbents}

Isoniazid (INH), with common name isonicotinic acid hydrazide has been well known as an essential anti-TB model drug at present. ${ }^{57}$ The structure of INH consists of two different reactive groups, pyridine $\mathrm{N}$ and hydrazine functionalities, allowing it as a bioactive bifunctional linker to link the other two monomers into frameworks. In our design, the pyridine $\mathrm{N}$ atoms of INH and amide $\mathrm{H}$ atoms of $\mathrm{BTCH}$ as hydrogen-bond acceptors and donors have been used to construct hydrogen bonds, whereas hydrazine of INH and aldehyde of TPA have been used for the preparation of hydrazone linkages. The combination of these hydrogen-bonds and hydrazone linkages using a bifunctional linker unit thus connects two different units with amino and aldehyde functionalities into a single $\mathrm{H}_{\mathrm{C}} \mathrm{OP}$ material.

Typically, pha- $\mathrm{H}_{\mathrm{C}} \mathrm{OP}-1$ was synthesized by solvothermal reaction of benzene-1,3,5-tricarbohydrazide (BTCH), isoniazid (INH) and terephthalaldehyde (TPA) in dimethyl sulphoxide (DMSO) with $\mathrm{CF}_{3} \mathrm{COOH}$ (TFA) as catalyst, at $100{ }^{\circ} \mathrm{C}$ for 1 hour, which afforded a yellow solid with $85 \%$ yield (Scheme 1 ). The pha- $\mathrm{H}_{\mathrm{C}} \mathrm{OPs}$ were characterized by TGA, FT-IR, FE-SEM, TEM, HR-TEM, nitrogen adsorption, ${ }^{13} \mathrm{C} \mathrm{CP} / \mathrm{MAS}$ NMR and PXRD.

To gain structural information about the pha- $\mathrm{H}_{\mathrm{C}} \mathrm{OPs},{ }^{13} \mathrm{C} \mathrm{CP} /$ MAS NMR as well as FT-IR were acquired. As shown in Fig. S3, $\dagger$ the FT-IR spectra of pha- $\mathrm{H}_{\mathrm{C}} \mathrm{OPs}$ show stretching modes at $1253 \mathrm{~cm}^{-1}$ that are characteristic of $\nu_{\mathrm{C}=\mathrm{N}}$ moieties. The characteristic peak of isoniazid at $1660 \mathrm{~cm}^{-1}$ in the pha- $\mathrm{H}_{\mathrm{C}} \mathrm{OPs}$ whereas at $1667 \mathrm{~cm}^{-1}$ in free isoniazid, is due to the amide $(\mathrm{C}=$ O stretching), consistent with a previous report. ${ }^{58}$ This indicates the successful incorporation of isoniazid into the network. The BTCH displays a strong band at $3299 \mathrm{~cm}^{-1}$ corresponding to stretching vibration of free amine. In the pha- $\mathrm{H}_{\mathrm{C}} \mathrm{OPs}$, the former band disappears, while a strong band appears at $3032 \mathrm{~cm}^{-1}$ indicating the $\mathrm{H}$-bonding exist. ${ }^{59}$ Solid-state ${ }^{13} \mathrm{C} \mathrm{CP} /$ MAS NMR analysis provides further confirmation that pha$\mathrm{H}_{\mathrm{C}} \mathrm{OPs}$ are constructed from the hydrazone bonds. As shown in Fig. 1, the presence of $-\mathrm{NH}-\mathrm{N}=\mathrm{C}$ - bonds formed between TPA and INH or BTCH are proved by the characteristic signals at $150.4 \mathrm{ppm}$. Except from the hydrazone bonds, all of the resonance signals between 120 and 170 ppm correspond to carbon atoms of the BTCH, INH and phenyl linkers.

In order to probe the long-range structure of pha- $\mathrm{H}_{\mathrm{C}} \mathrm{OPs}$, transmission electron microscopy (TEM) and powder X-ray diffraction (PXRD) studies were performed. As shown in Fig. 2a and c, the TEM and HR-TEM images illustrate that the pha- $\mathrm{H}_{\mathrm{C}} \mathrm{OPs}$ are isolated spherical nanoparticles with an average diameter of about $20 \mathrm{~nm}$. FE-SEM was used to investigate the morphology of the pha- $\mathrm{H}_{\mathrm{C}} \mathrm{OPs}$ which cast from the dichloromethane suspension on the Si wafer. SEM images also give similar spherical aggregates with an average diameter of $20 \mathrm{~nm}$, as shown in Fig. $2 b$ and d. The PXRD pattern of the pha- $\mathrm{H}_{\mathrm{C}} \mathrm{OPs}$ is amorphous in nature as shown in Fig. S4. $\dagger$

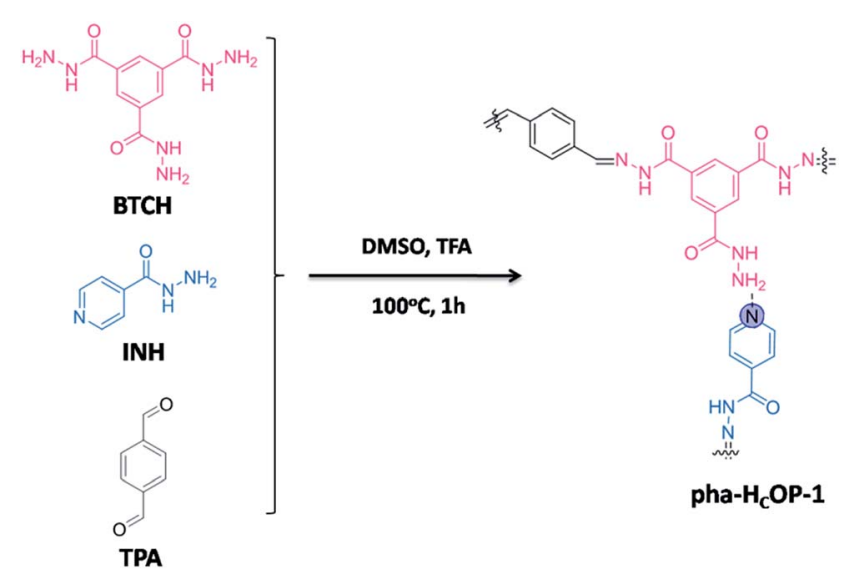

Scheme 1 Schematic illustration of pha- $\mathrm{H}_{\mathrm{C}} \mathrm{OP}-1$. Involving the formation of two types of linkages. 


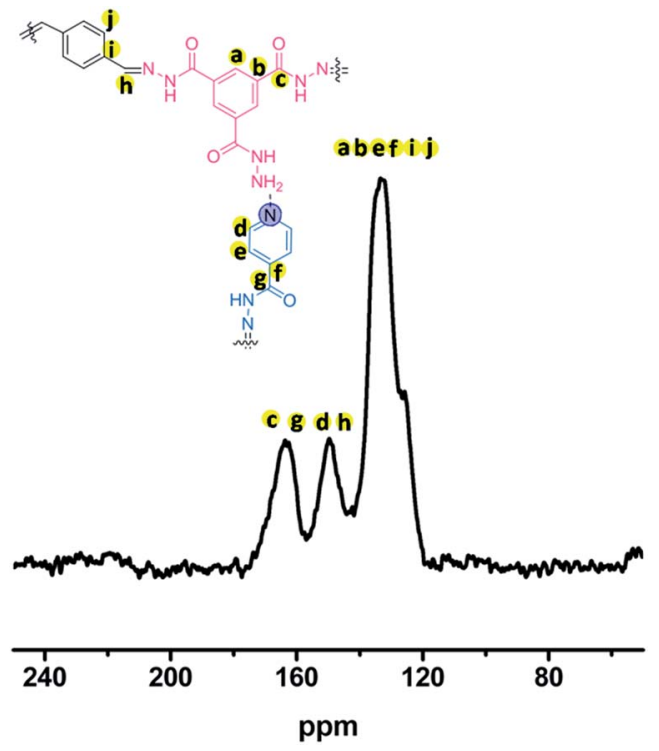

Fig. $1{ }^{13} \mathrm{C}$ CP/MAS NMR spectrum of the pha- $\mathrm{H}_{\mathrm{C}} \mathrm{OP}-1$.

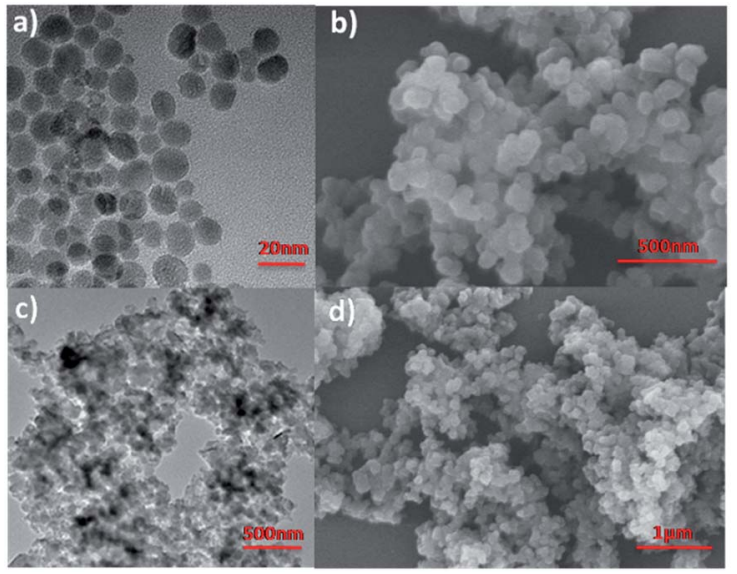

Fig. 2 TEM images (a and $c$ ) and SEM images ( $b$ and $d$ ) of the pha$\mathrm{H}_{\mathrm{C}} \mathrm{OP}-1$.

The thermal stability was investigated by TGA under air. TGA shows a good thermal stability of the pha- $\mathrm{H}_{\mathrm{C}} \mathrm{OPs}$, with $30 \%$ weight loss at temperature of $346{ }^{\circ} \mathrm{C}$ (Fig. S5 $\dagger$ ). The porosity of the pha- $\mathrm{H}_{\mathrm{C}} \mathrm{OPs}$ was revealed by nitrogen sorption measurements at $77 \mathrm{~K}$. The pha- $\mathrm{H}_{\mathrm{C}} \mathrm{OPs}$ were degassed at $100{ }^{\circ} \mathrm{C}$ for $8 \mathrm{~h}$ before analysis. As shown in Fig. 3, the pha- $\mathrm{H}_{\mathrm{C}} \mathrm{OPs}$ exhibit type II adsorption according to the IUPAC classification. The Brunauer-Emmett-Teller (BET) surface area and the total pore volume for pha- $\mathrm{H}_{\mathrm{C}} \mathrm{OP}-1$ are $217.31 \mathrm{~m}^{2} \mathrm{~g}^{-1}$ and $1.048 \mathrm{~cm}^{3} \mathrm{~g}^{-1}$. Majority of gas is absorbed at high relative pressures $P / P_{0}>0.90$. Moreover, the pore size in pha- $\mathrm{H}_{\mathrm{C}} \mathrm{OPs}$ mainly centered at $2.45 \mathrm{~nm}$, as obtained by the non-local density functional theory (NLDFT).

\section{Iodine capture}

The good porous characters of these pha- $\mathrm{H}_{\mathrm{C}} \mathrm{OPs}$ prompted us to investigate their adsorption properties for radical $\mathrm{I}_{2}$ molecules.
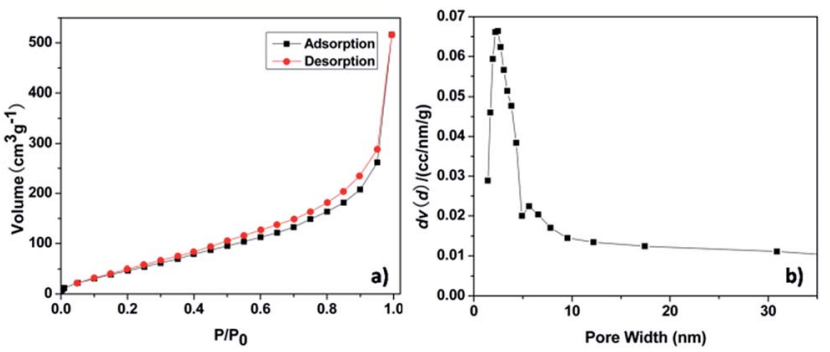

Fig. $3 \quad N_{2}$ adsorption-desorption isotherm (a) and pore size distribution (b) of pha- $\mathrm{H}_{\mathrm{C}} \mathrm{OP}-1$.

We successfully carried out efficient iodine enrichment based on pha- $\mathrm{H}_{\mathrm{C}} \mathrm{OPs}$ by exposing pha- $\mathrm{H}_{\mathrm{C}} \mathrm{OPs}$ powder to excess iodine vapor in a closed system at $353 \mathrm{~K}$ and ambient pressure. As time went on, the color of the solid powder changed apparently, and the quality of pha- $\mathrm{H}_{\mathrm{C}} \mathrm{OPs}$ after capture was measured by the gravimetric method. The adsorption equilibrium of pha- $\mathrm{H}_{\mathrm{C}} \mathrm{OPs}$ were reached quickly (1-4 h) and no obvious weight gain of the samples were observed after $6 \mathrm{~h}$. The saturated iodine loading of pha- $\mathrm{H}_{\mathrm{C}} \mathrm{OPs}$ was measured to be $131 \mathrm{wt} \%$ (Fig. 4a). With this value, pha- $\mathrm{H}_{\mathrm{C}} \mathrm{OP}-1$ could be comparable to some metal-organic frameworks (MOFs) ${ }^{60}$ and even some recent $\mathrm{CMPNs}^{48}$ (Table S1 $\dagger$ ), while far exceeding the commercial activated carbon with $30 \mathrm{wt} \%$ iodine vapor uptake capability. ${ }^{40}$ The high iodine sorption capacity of pha- $\mathrm{H}_{\mathrm{C}} \mathrm{OP}-1$ is considered to be attributed to three main reasons: first, the specific surface area and porous structures may improve the adsorption capacity for iodine; second, the plentiful $\pi$-conjugated phenyl rings would lead to an increase in iodine uptake; third, the introducing of -CO-NH- functionality could lead to an enhancement for their interactions with iodine molecules.

For the iodine-loaded samples (named as $\mathrm{I}_{2} @ p h a-\mathrm{H}_{\mathrm{C}} \mathrm{OPs}$ ), the XPS spectroscopy indicated that the valence of the iodine adsorbed on the surface of pha- $\mathrm{H}_{\mathrm{C}} \mathrm{OPs}$ is zero, confirming that the iodine remains neutral (Fig. 4b). After $\mathrm{I}_{2} @$ pha- $\mathrm{H}_{\mathrm{C}} \mathrm{OPs}$ were washed with ethanol three times, XPS verified the iodine encapsulated in the pores transformed into various polyiodide states such as $\mathrm{I}_{3}{ }^{-}$suggesting chemisorption taking place together with the physisorption (Fig. S6 $†$ ). ${ }^{61}$ Furthermore, the FT-IR spectra illustrated that the iodine-loaded pha- $\mathrm{H}_{\mathrm{C}} \mathrm{OPs}$ exhibited considerably enhanced $\mathrm{N}-\mathrm{H}$ stretching vibrations compared to parent pha- $\mathrm{H}_{\mathrm{C}} \mathrm{OPs}$, suggesting noncovalent interactions between amine groups of pha- $\mathrm{H}_{\mathrm{C}} \mathrm{OPs}$ with iodine
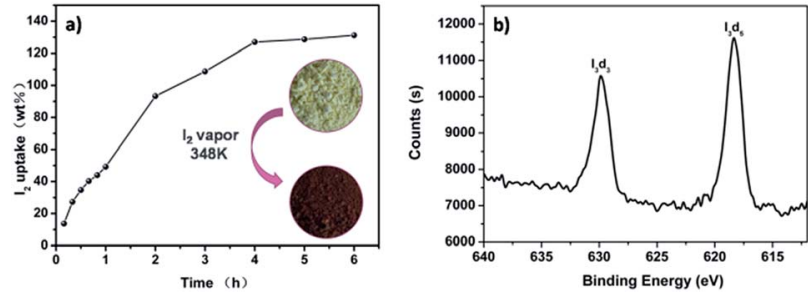

Fig. 4 (a) Gravimetric uptake of iodine as a function of time at $353 \mathrm{~K}$. Inset photographs showing the color change when pha- $\mathrm{H}_{\mathrm{C}} \mathrm{OP}-1$ was exposed to iodine vapor $4 \mathrm{~h}$. (b) XPS spectrum of $\mathrm{I}_{2}$ apha- $\mathrm{H}_{\mathrm{C}} \mathrm{OP}-1$. 
a)

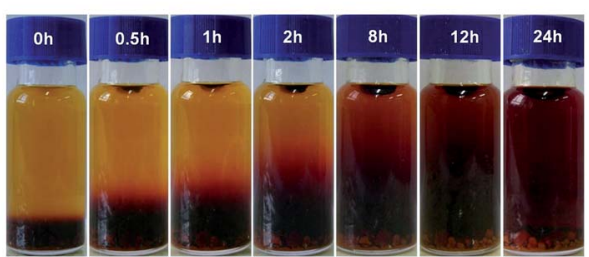

b)

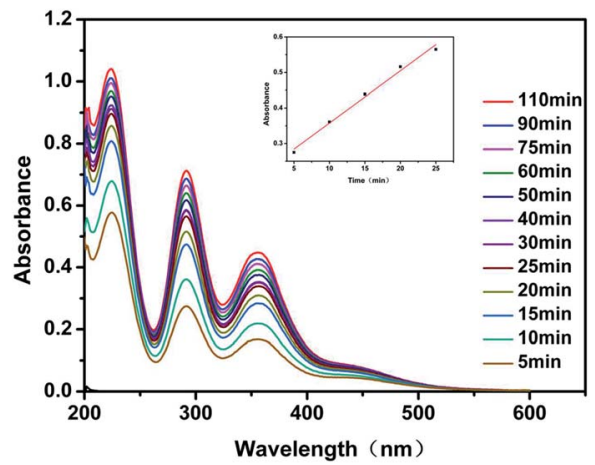

Fig. 5 (a) Photographs showing progress of the iodine release from pha- $\mathrm{H}_{\mathrm{C}} \mathrm{OP}-1$ when the $\mathrm{I}_{2}$ apha- $\mathrm{H}_{\mathrm{C}} \mathrm{OP}-1$ were immersed in methanol. (b) Temporal evolution of UV-vis adsorption spectra of the iodine released from the $\mathrm{I}_{2} @$ apha- $\mathrm{H}_{\mathrm{C}} \mathrm{OP}-1$ in $10 \mathrm{~mL}$ of methanol. Inset: fit curves of the controlled of iodine at different time intervals.

(Fig. S7 $\dagger$ ). This is most likely due to the charge-transfer (CT) interactions between the $\mathrm{N}-\mathrm{H}$ and $\mathrm{C}=\mathrm{O}$ units as well as aromatic electron donor and iodine acceptor according to a previous literature. ${ }^{62}$ Thus, the $-\mathrm{CO}-\mathrm{NH}-$ fragments and aromatic rings in the polymer skeleton might play a crucial role in the iodine capture.

Furthermore, we found that the iodine adsorption of pha$\mathrm{H}_{\mathrm{C}} \mathrm{OP}-1$ is reversible. To this end, the $\mathrm{I}_{2} @ p h a-\mathrm{H}_{\mathrm{C}} \mathrm{OPs}$ were immersed in several organic solvents such as ethanol, methanol and hexane. As shown in Fig. 5a, when the $\mathrm{I}_{2} @$ pha- $\mathrm{H}_{\mathrm{C}} \mathrm{OPs}$ were immersed in methanol, the color of the solution was observed from colorless to dark brown. At suitable time intervals, the absorbency of solvent was monitored at the $288 \mathrm{~nm}$ show the release kinetics of sample $\mathrm{I}_{2} @$ @pha- $\mathrm{H}_{\mathrm{C}} \mathrm{OPs}$, and the $\mathrm{I}_{2}$ delivery is empirically adjusted as a zero-order reaction (Fig. 5b).

\section{Iodine adsorption}

Moreover, the iodine adsorption of pha- $\mathrm{H}_{\mathrm{C}} \mathrm{OPs}$ was further investigated by immersing pha- $\mathrm{H}_{\mathrm{C}} \mathrm{OPs}(10 \mathrm{mg})$ in iodine/hexane solution (100-350 $\left.\mathrm{mg} \mathrm{L}^{-1}, 10 \mathrm{~mL}\right)$. And with adsorption process prolong, the dark purple solutions of iodine fade slowly to very pale red and finally colorless. The results demonstrated that the iodine was encapsulated into the pha- $\mathrm{H}_{\mathrm{C}} \mathrm{OP}$ networks to successively generate iodine-loaded systems in solution.

\section{Adsorption dynamics analysis}

In order to understand the iodine adsorption kinetics in pha$\mathrm{H}_{\mathrm{C}} \mathrm{OP}-1$, the experimental data are processed by pseudo-first and second order kinetic models. The pseudo-first-order and pseudo-second-order kinetic models can be described as: ${ }^{63,64}$

$$
\begin{gathered}
\ln \left(q_{\mathrm{e}}-q_{t}\right)=\ln q_{\mathrm{e}}-k_{1} t \\
\frac{t}{q_{t}}=\frac{1}{k_{2} q_{\mathrm{e}}^{2}}+\frac{t}{q_{\mathrm{e}}}
\end{gathered}
$$

where $q_{\mathrm{t}}$ and $q_{\mathrm{e}}$ are the amounts of the iodine adsorbed $\left(\mathrm{mg} \mathrm{g}^{-1}\right)$ at the time $t(\mathrm{~h})$ and equilibrium time, respectively; $k_{1}\left(\mathrm{~h}^{-1}\right)$ and $k_{2}\left(\left(\mathrm{~g} \mathrm{mg}^{-1}\right) \mathrm{h}^{-1}\right)$ are the kinetic rate constants for the pseudofirst-order and the second-order models, respectively.

The effect of contact time and the initial solution concentration on the uptake of iodine by pha- $\mathrm{H}_{\mathrm{C}} \mathrm{OP}-1$ are presented in Fig. 6a. As expected, the amount of iodine adsorbed by pha- $\mathrm{H}_{\mathrm{C}} \mathrm{OP}-$ 1 increases with increasing contact time and increasing initial iodine concentration. $120 \mathrm{~h}$ were required for the pha- $\mathrm{H}_{\mathrm{C}} \mathrm{OP}-1$ to reach adsorption equilibrium. In the first $12 \mathrm{~h}$, the adsorption capacity increased quickly, and then gradually became slowly until reaches the adsorption equilibrium in about $120 \mathrm{~h}$. The maximum adsorption capacity and removal efficiency for pha$\mathrm{H}_{\mathrm{C}} \mathrm{OP}-1$ were found to be $94.70 \mathrm{mg} \mathrm{g}^{-1} \& 93.03 \%, 142.88 \mathrm{mg} \mathrm{g}^{-1}$ \& $94.70 \%, 191.06 \mathrm{mg} \mathrm{g}^{-1} \& 95.25 \%, 235.30 \mathrm{mg} \mathrm{g}^{-1} \& 95.53 \%$,

a)

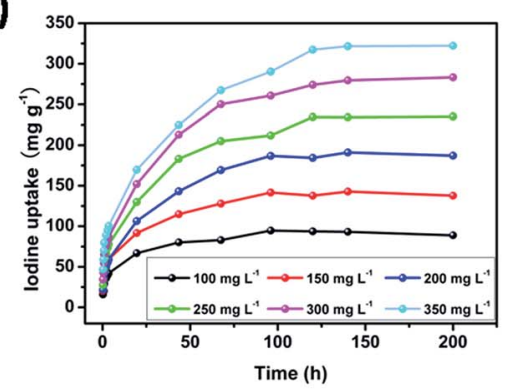

b)

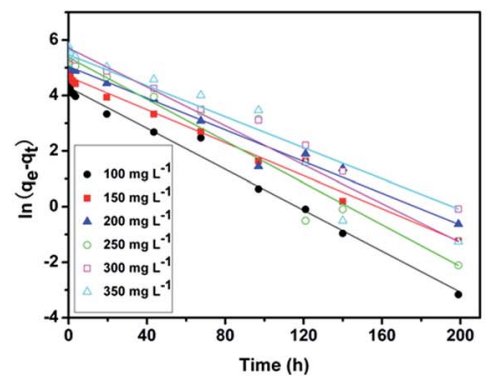

c)

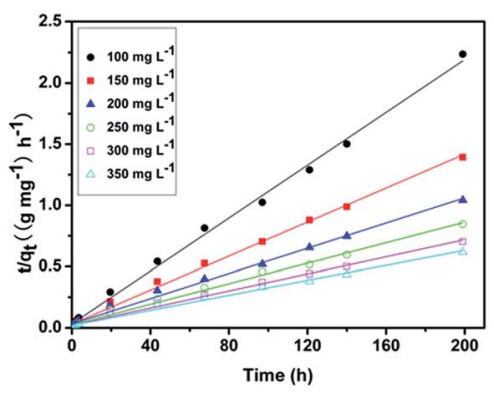

Fig. 6 (a) Kinetic studies of iodine adsorption by pha- $\mathrm{H}_{C} \mathrm{OP}-1$ in hexane solution with different concentrations of $100-350 \mathrm{mg} \mathrm{L}^{-1}$. (b) Lagergren plots for iodine adsorption by pha- $\mathrm{H}_{\mathrm{C}} \mathrm{OP}-1$ at different initial iodine concentrations. (c) Pseudo-second-order kinetics of iodine adsorption by pha- $\mathrm{H}_{\mathrm{C}} \mathrm{OP}-1$ at different initial iodine concentrations. 
Table 1 Kinetic parameters for the adsorption of iodine by pha- $\mathrm{H}_{\mathrm{C}} \mathrm{OP}-1$

\begin{tabular}{|c|c|c|c|c|c|c|c|}
\hline & $Q_{\mathrm{e}}(\exp )\left(\mathrm{mg} \mathrm{g}^{-1}\right)$ & \multicolumn{3}{|c|}{ Pseudo-first order kinetics } & \multicolumn{3}{|c|}{ Pseudo-second order kinetics } \\
\hline 150 & 142.88 & 0.030 & 107.24 & 0.98 & 0.0016 & 144.93 & 0.99 \\
\hline 200 & 191.06 & 0.029 & 155.35 & 0.97 & 0.00080 & 196.08 & 0.99 \\
\hline 250 & 235.30 & 0.038 & 214.78 & 0.94 & 0.00068 & 238.10 & 0.99 \\
\hline
\end{tabular}

$283.18 \mathrm{mg} \mathrm{g}^{-1} \& 94.12 \%$, and $322.27 \mathrm{mg} \mathrm{g}^{-1} \& 94.39 \%$ with the initial concentration of $100-350 \mathrm{mg} \mathrm{L}^{-1}$, respectively.

Fig. $6 \mathrm{~b}$ and $\mathrm{c}$ show the curve-fitting plots of the pseudo-firstand second-order models, respectively. As shown in Table 1, the adsorption process of pha- $\mathrm{H}_{\mathrm{C}} \mathrm{OP}-1$ to iodine fits well in pseudosecond order kinetics model and provides much better linear correlation coefficient $R^{2}(0.99,0.99,0.99,0.99,0.99$ and 0.99) than that of pseudo first-order kinetic model $(0.99,0.98,0.97$, 0.94, 0.99 and 0.94), which indicates that the iodine adsorption process in pha- $\mathrm{H}_{\mathrm{C}} \mathrm{OP}-1$ was dominated by the pseudo-secondorder kinetic model instead of the pseudo-first-order model. Furthermore, the closer $q_{\mathrm{e}}$,cal calculated by pseudo-second-order model was also in accordance with the aforementioned conclusion. Moreover, this pseudo-second-order model effectively described the chemisorption-type process, and further verified the assumption of strong interaction between the surface and the adsorbate, confirming the formation of charge transfer complexes between iodine and the pha- $\mathrm{H}_{\mathrm{C}} \mathrm{OP}-1$ framework. ${ }^{65}$

\section{Adsorption isotherms analysis}

Temperature is another factor determining the maximum adsorption capacity. So batch experiments were performed in the temperature range of $288-308 \mathrm{~K}$ at different initial iodine concentrations (200-1000 $\mathrm{mg} \mathrm{L}^{-1}$ ). The experimental adsorption isotherm data were then analyzed by classical Langmuir and Freundlich adsorption isotherms.

The Langmuir sorption isotherm is one of the most common isotherm equations which is based on several basic assumptions, including (i) the adsorbent is structurally homogeneous; (ii) it is monolayer adsorption on the solid surface of adsorbate; (iii) the active sites are independent. The Langmuir isotherm model can be represented as: ${ }^{\mathbf{6 6}}$

$$
\begin{gathered}
q_{\mathrm{e}}=\frac{K_{\mathrm{L}} C_{\mathrm{e}}}{1+a_{\mathrm{L}} C_{\mathrm{e}}} \\
\frac{C_{\mathrm{e}}}{q_{\mathrm{e}}}=\frac{1}{K_{\mathrm{L}}}+\frac{a_{\mathrm{L}} C_{\mathrm{e}}}{K_{\mathrm{L}}}
\end{gathered}
$$

where $q_{\mathrm{e}}\left(\mathrm{mg} \mathrm{g}^{-1}\right)$ is the amount of iodine adsorbed on the adsorbent at equilibrium, $C_{\mathrm{e}}\left(\mathrm{mg} \mathrm{L}^{-1}\right)$ is the equilibrium concentration of iodine in the solution, and $K_{\mathrm{L}}\left(\mathrm{L} \mathrm{g} \mathrm{g}^{-1}\right)$ and $a_{\mathrm{L}}$ $\left(\mathrm{L} \mathrm{mg}^{-1}\right.$ ) are the Langmuir constants. In addition, the $q_{\mathrm{m}}$, the maximum adsorption capacity of the adsorbent, is numerically equal to $K_{\mathrm{L}} / a_{\mathrm{L}}$. In order to predict whether the adsorption process is favourable or unfavourable, the isotherm shape can be classified by a dimensionless constant " $R_{\mathrm{L}}$ ", which was determined by the following equation: ${ }^{67}$

$$
R_{\mathrm{L}}=\frac{1}{1+a_{\mathrm{L}} C_{0}}
$$

where $C_{0}\left(\mathrm{mg} \mathrm{L}^{-1}\right)$ is the initial concentrations of iodine in the solution and $a_{\mathrm{L}}\left(\mathrm{L} \mathrm{mg}^{-1}\right)$ is the Langmuir constant. Value of $r<1$ represents the favourable adsorption and value greater than one represents unfavourable adsorption. The parameter $R_{\mathrm{L}}$ indicates the shape of the isotherm accordingly:

$R_{\mathrm{L}}>1$ unfavourable, $R_{\mathrm{L}}=1$ linear, $0<R_{\mathrm{L}}<1$ favourable, $R_{\mathrm{L}}=$ 0 irreversible.

On the contrary, the well-known Freundlich isotherm, is based on adsorption on heterogeneous surface. The Freundlich isotherm can be represented as: ${ }^{68}$

$$
\begin{gathered}
q_{\mathrm{e}}=K_{\mathrm{F}} C_{\mathrm{e}}^{1 / n} \\
\ln q_{\mathrm{e}}=\ln K_{\mathrm{F}}+\frac{1}{n} \ln c_{\mathrm{e}}
\end{gathered}
$$

where $q_{\mathrm{e}}\left(\mathrm{mg} \mathrm{g}^{-1}\right)$ and $c_{\mathrm{e}}\left(\mathrm{mg} \mathrm{L}^{-1}\right)$ have the same definitions as above mentioned. $K_{\mathrm{F}}\left(\mathrm{L} \mathrm{g}^{-1}\right)$ is the Freundlich constant which
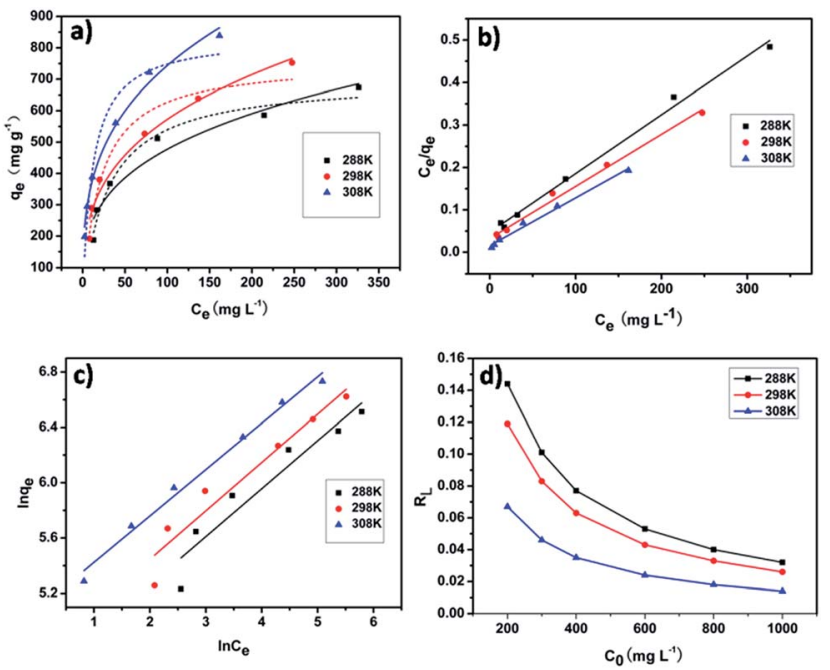

Fig. 7 (a) Data fitting with Langmuir and Freundlich adsorption isotherms of iodine adsorption by pha- $\mathrm{H}_{\mathrm{C}} \mathrm{OP}-1$ at different temperatures from 288 to $303 \mathrm{~K}$; solid lines: Langmuir model, dashed lines: Freundlich model. (b) Langmuir and (c) Freundlich linear fitting for the iodine adsorption by pha- $\mathrm{H}_{\mathrm{C}} \mathrm{OP}-1$. (d) Separation factor for iodine adsorption by pha- $\mathrm{H}_{\mathrm{C}} \mathrm{OP}-1$. 
Table 2 Langmuir isotherm parameters for the adsorption of iodine by pha- $\mathrm{H}_{\mathrm{C}} \mathrm{OP}-1$

\begin{tabular}{lllll}
\hline Langmuir isotherm & Temperature (K) & $Q_{\mathrm{m}}$ & $K_{\mathrm{L}}$ & $R^{2}$ \\
\hline $\mathrm{L}$ & 288 & 714.29 & 0.030 & 0.99 \\
& 298 & 833.33 & 0.037 & 0.99 \\
& 308 & 909.09 & 0.069 & 0.99
\end{tabular}

Table 3 Freundlich isotherm parameters for the adsorption of iodine by pha- $\mathrm{H}_{\mathrm{C}} \mathrm{OP}-1$

\begin{tabular}{llrlr}
\hline $\begin{array}{l}\text { Freundlich } \\
\text { isotherm }\end{array}$ & $\begin{array}{l}\text { Temperature } \\
(\mathrm{K})\end{array}$ & \multicolumn{1}{c}{$K_{\mathrm{L}}$} & $R^{2}$ & $1 / n$ \\
\hline $\mathrm{F}$ & 288 & 96.49 & 0.91 & 0.35 \\
& 298 & 115.18 & 0.93 & 0.35 \\
& 308 & 162.08 & 0.98 & 0.34 \\
& & & & \\
\hline
\end{tabular}

indicates the adsorption capacity, and $1 / n$ is the heterogeneity factor. The value of slope $1 / n$ ranging between 0 and 1 , is a measure of the deviation from linearity of the adsorption. A value for $1 / n$ below unity indicates the adsorption is chemical while $1 / n$ above unity implies that adsorption process is a favorable physical process. In addition, when the value of $1 / n$ is equal to unity, the adsorption is linear.

As shown in Fig. 7a-c, the experimental results showed that Langmuir adsorption isotherm could be well describe the iodine adsorption by pha- $\mathrm{H}_{\mathrm{C}} \mathrm{OPs}$. The values $\left(q_{\mathrm{m}}, K_{\mathrm{L}}, K_{\mathrm{F}}, R_{\mathrm{L}}, n\right.$ and $R^{2}$ ) of the adsorption constants obtained from each model are tabulated in Tables 2 and 3, respectively. The values of $R^{2}$ (0.91, 0.93 and 0.98$)$ of the Freundlich isotherm were much lower than the values of $R^{2}$ (0.99, 0.99 and 0.99) of the Langmuir isotherm. This suggests that the adsorption of iodine by pha$\mathrm{H}_{\mathrm{C}} \mathrm{OP}-1$ is monolayer-type and homogeneous of iodine molecule on the surface of pha- $\mathrm{H}_{\mathrm{C}} \mathrm{OPs}$. The maximum adsorption capacity $\left(q_{\mathrm{m}}\right)$ for iodine derived from the Langmuir equation are 714.29, 833.33 and $909.09 \mathrm{mg} \mathrm{g}^{-1}$ for 288,298 and $308 \mathrm{~K}$, respectively. Indeed, the $q_{\mathrm{m}}$ is proportional to the solution temperature, indicating an increased affinity of iodine toward pha- $\mathrm{H}_{\mathrm{C}} \mathrm{OPs}$ surface at higher temperature.

It was found that the calculated value of $R_{\mathrm{L}}$ for iodine adsorption by pha- $\mathrm{H}_{\mathrm{C}} \mathrm{OPs}$ were in the range of $0.032-0.144,0.026-$ 0.119 and $0.014-0.067$ at 288,298 and $308 \mathrm{~K}$, respectively. These values indicate that the adsorption of iodine by pha- $\mathrm{H}_{\mathrm{C}} \mathrm{OPs}$ is a favorable adsorption and endothermal. As shown in Fig. 7d, the $R_{\mathrm{L}}$ values decreased with the iodine concentrations showed that adsorption was more favorable at lower concentration.

\section{Adsorption thermodynamics analysis}

The mechanism involved in the adsorption, can be explained on the basis of some thermodynamic parameters such as the variation in free energy $(\Delta G)\left(\mathrm{kJ} \mathrm{mol}^{-1}\right)$, enthalpy $(\Delta H)$ $\left(\mathrm{kJ} \mathrm{mol}^{-1}\right)$, and entropy $(\Delta S)\left(\mathrm{kJ} \mathrm{mol}^{-1}\right)$, which can be calculated as follows: ${ }^{69}$
Table 4 Values of thermodynamic parameters for the adsorption of iodine by pha- $\mathrm{H}_{\mathrm{C}} \mathrm{OP}-1$

\begin{tabular}{|c|c|c|c|c|c|}
\hline \multirow{2}{*}{$\begin{array}{l}C_{0} \\
\left(\mathrm{mg} \mathrm{L}^{-1}\right)\end{array}$} & \multicolumn{3}{|c|}{$\Delta G\left(\mathrm{~kJ} \mathrm{~mol}^{-1}\right)$} & \multirow{2}{*}{$\begin{array}{l}\Delta H \\
\left(\mathrm{~kJ} \mathrm{~mol}^{-1}\right)\end{array}$} & \multirow{2}{*}{$\begin{array}{l}\Delta S \\
\left(\mathrm{~kJ} \mathrm{~mol}^{-1} \mathrm{~K}^{-1}\right)\end{array}$} \\
\hline & $288 \mathrm{~K}$ & $298 \mathrm{~K}$ & $308 \mathrm{~K}$ & & \\
\hline 300 & -6.76 & -8.30 & -10.29 & 43.95 & 0.18 \\
\hline 400 & -5.83 & -7.31 & -9.04 & 40.49 & 0.16 \\
\hline 600 & -4.20 & -4.89 & -6.83 & 33.39 & 0.13 \\
\hline 800 & -2.40 & -3.82 & -5.67 & 44.59 & 0.16 \\
\hline 1000 & -1.74 & -2.76 & -4.22 & 33.89 & 0.12 \\
\hline
\end{tabular}

$$
\begin{gathered}
K_{\mathrm{d}}=\frac{q_{\mathrm{e}}}{c_{\mathrm{e}}} \\
\Delta G=-R T \ln \left(K_{\mathrm{d}}\right) \\
\ln \left(K_{\mathrm{d}}\right)=\frac{\Delta S}{R}-\frac{\Delta H}{R T}
\end{gathered}
$$

where $K_{\mathrm{d}}\left(\mathrm{L} \mathrm{g}^{-1}\right)$ is the standard thermodynamic equilibrium constant defined by $q_{\mathrm{e}} / C_{\mathrm{e}}, R$ is the universal gas constant (8.314) ( $\mathrm{J} \mathrm{mol}^{-1} \mathrm{~K}^{-1}$ ) and $T$ is the temperature (K). $\Delta H$ and $\Delta S$ could be calculated from the slopes and intercepts of the linear plot of $\ln K_{\mathrm{d}}$ versus $1 / T$.

The various Gibbs free energy $(\Delta G)$, adsorptions enthalpy $(\Delta H)$ and entropy $(\Delta S)$ for pha- $\mathrm{H}_{\mathrm{C}} \mathrm{OPs}$ at the three temperatures studied were given in Table 4 . The $\Delta G$ values calculated based on eqn (11) ranged from -6.76 to $-10.29 \mathrm{~kJ} \mathrm{~mol}^{-1},-5.83$ to $-9.04 \mathrm{~kJ} \mathrm{~mol}^{-1},-4.20$ to $-6.83 \mathrm{~kJ} \mathrm{~mol}^{-1},-2.40$ to $-5.67 \mathrm{~kJ} \mathrm{~mol}^{-1}$ and -1.74 to $-4.22 \mathrm{~kJ} \mathrm{~mol}^{-1}$, respectively, corresponding to temperatures of $288 \mathrm{~K}, 298 \mathrm{~K}$ and $308 \mathrm{~K}$ at different initial iodine concentrations. The decrease of $\Delta G$ values with the rise in temperature implies that higher temperature favors iodine sorption. The values of $\Delta H$ and $\Delta S$ were determined from the van't Hoff plots to be $43.95 \mathrm{~kJ} \mathrm{~mol}^{-1}$ and $0.18 \mathrm{~kJ} \mathrm{~mol}^{-1}, 40.49 \mathrm{~kJ} \mathrm{~mol}^{-1}$ and $0.16 \mathrm{~kJ} \mathrm{~mol}^{-1}$, $33.39 \mathrm{~kJ} \mathrm{~mol}^{-1}$ and $0.13 \mathrm{~kJ} \mathrm{~mol}^{-1}, 44.59 \mathrm{~kJ} \mathrm{~mol}^{-1}$ and $0.16 \mathrm{~kJ} \mathrm{~mol}^{-1}, 33.89 \mathrm{~kJ} \mathrm{~mol}^{-1}$ and $0.12 \mathrm{~kJ} \mathrm{~mol}^{-1}$ for different concentrations, respectively (Fig. 8). Thermodynamically, the

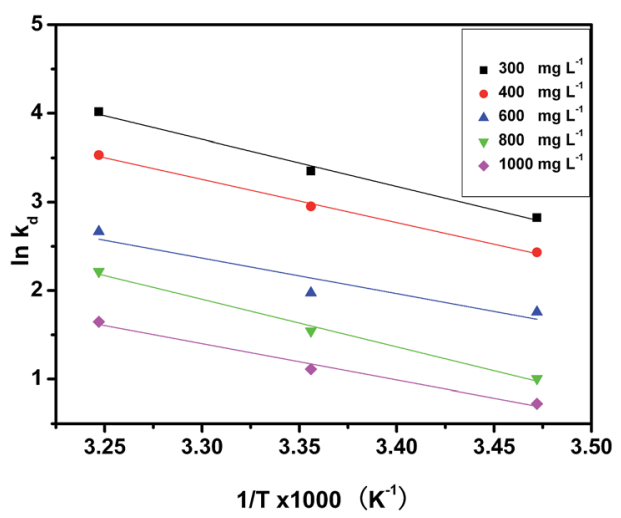

Fig. 8 van't Hoff plots to get the $\Delta H$ and $\Delta S$ of iodine adsorption by pha- $\mathrm{H}_{\mathrm{C}} \mathrm{OP}-1$. 
negative values of $\Delta G$ and the positive values of $\Delta H$ and $\Delta S$ at all temperatures, suggesting that the spontaneous and endothermic nature of the iodine adsorption by pha- $\mathrm{H}_{\mathrm{C}} \mathrm{OPs}$, and the adsorption is controlled by enthalpy. ${ }^{70}$ Moreover, the magnitude of $\Delta G$ and $\Delta H$ also indicates about the type of sorption process. ${ }^{71}$ In present study, the values of $\Delta G$ lies within the range of physisorption process whereas the values of $\Delta H$ corresponds to chemisorption range, suggesting chemisorption taking place together with the physisorption. ${ }^{72}$

\section{Conclusions}

In conclusion, the porous pharmaceutical hydrogen-bonded covalent organic polymers have been constructed with the formations of two types of bonds using the pharmaceutical isoniazid as a bifunctional linker. Remarkably, such pha- $\mathrm{H}_{\mathrm{C}} \mathrm{OPs}$ with porous property, and $\pi$-conjugated phenyl rings, as well as electronegative electron-donating - $\mathrm{CO}-\mathrm{NH}-$ building units provide a great potential in harmful volatile gases (including $\mathrm{I}_{2}$, $\mathrm{Br}_{2}$ and $\mathrm{Cl}_{2}$ ) enrichment. As a result, the maximum iodine uptake of 131 wt\% was obtained. This study not only sheds more light on extending of POP materials with new structures, but also may help lay the groundwork for the development of pha- $\mathrm{H}_{\mathrm{C}} \mathrm{OPs}$ for remediation of radioactive iodine to address environmental issues.

\section{Conflicts of interest}

There are no conflicts to declare.

\section{Acknowledgements}

This work was supported by the National Natural Science Foundation of China (Project No. 21601177) and the 111 project (B16020).

\section{Notes and references}

1 H. X. Deng, S. Grunder, K. E. Cordova, C. Valente, H. Furukawa, M. Hmadeh, F. Gandara, A. C. Whalley, Z. Liu, S. Asahina, H. Kazumori, M. O'Keeffe, O. Terasaki, J. F. Stoddart and O. M. Yaghi, Science, 2012, 336, 1018-1023.

2 Y. Chen, H. J. Cui, J. Q. Zhang, K. Zhao, D. F. Ding, J. Guo, L. S. Li, Z. Y. Tian and Z. Y. Tang, RSC Adv., 2015, 5, 92573-92576.

3 J. L. Pan, S. Jia, G. K. Li and Y. L. Hu, Anal. Chem., 2015, 87, 3373-3381.

4 C. J. Zhang, G. K. Li and Z. M. Zhang, J. Chromatogr. A, 2015, 1419, 1-9.

5 H. C. Zhou, J. R. Long and O. M. Yaghi, Chem. Rev., 2012, 112, 673-674.

6 S. Y. Ding and W. Wang, Chem. Soc. Rev., 2013, 42, 548-568. 7 S. Lin, C. S. Diercks, Y. B. Zhang, N. Kornienko, E. M. Nichols, Y. Zhao, A. R. Paris, D. Kim, P. Yang, O. M. Yaghi and C. J. Chang, Science, 2015, 349, 1208-1213.
8 M. G. Schwab, B. Fassbender, H. W. Spiess, A. Thomas, X. L. Feng and K. Müllen, J. Am. Chem. Soc., 2009, 131, 7216-7217.

9 Y. L. Hu, H. X. Lian, L. J. Zhou and G. K. Li, Anal. Chem., 2015, 87, 406-412.

10 A. P. Cote, A. I. Benin, N. W. Ockwig, M. O'Keeffe, A. J. Matzger and O. M. Yaghi, Science, 2005, 310, 1166-1170.

11 P. Kuhn, M. Antonietti and A. Thomas, Angew. Chem., Int. Ed., 2008, 47, 3450-3453.

12 C. F. Martin, E. Stockel, R. Clowes, D. J. Adams, A. I. Cooper, J. J. Pis, F. Rubiera and C. Pevida, J. Mater. Chem., 2011, 21, 5475-5483.

13 R. Dawson, D. J. Adams and A. I. Cooper, Chem. Sci., 2011, 2, 1173-1177.

14 N. B. McKeown and P. M. Budd, Macromolecules, 2010, 43, 5163-5176.

15 T. Ben, H. Ren, S. Q. Ma, D. P. Cao, J. H. Lan, X. F. Jing, W. C. Wang, J. Xu, F. Deng, J. M. Simmons, S. L. Qiu and G. S. Zhu, Angew. Chem., Int. Ed., 2009, 48, 9457-9460.

16 X. D. Li, S. Q. Feng, F. Guo, X. Y. Liu, J. X. Yu and Z. W. Hou, RSC Adv., 2016, 6, 21517-21525.

17 S. Y. Ding, M. Dong, Y. W. Wang, Y. T. Chen, H. Z. Wang, C. Y. Su and W. Wang, J. Am. Chem. Soc., 2016, 138, 30313037.

18 C. A. Wang, Y. F. Han, Y. W. Li, K. Nie, X. L. Cheng and J. P. Zhang, RSC Adv., 2016, 6, 34866-34871.

19 X. Feng, X. Ding and D. Jiang, Chem. Soc. Rev., 2012, 41, 6010-6022.

20 T. Mitra, R. S. Bhavsar, D. J. Adams, P. M. Budd and A. I. Cooper, Chem. Commun., 2016, 52, 5581-5584.

21 Y. Zhu, H. Long and W. Zhang, Chem. Mater., 2013, 25, 16301635.

22 D. Thirion, Y. Kwon, V. Rozyyev, J. Byun and C. T. Yavuz, Chem. Mater., 2016, 28, 5592-5595.

23 R. Shen and H. Z. Liu, RSC Adv., 2016, 6, 37731-37739.

24 L. M. Liu, H. Kai, K. Nagamine, Y. Ogawa and M. Nishizawa, RSC Adv., 2016, 6, 48630-48635.

25 Y. F. Xu, Z. Li, F. Zhang, X. D. Zhuang, Z. Zeng and J. J. Wei, RSC Adv., 2016, 6, 30048-30055.

26 W. J. Zhang, B. Aguila and S. Q. Ma, J. Mater. Chem. A, 2017, 5, 8795-8824.

27 Q. Sun, Z. Dai, X. Meng, L. Wang and F. S. Xiao, ACS Catal., 2015, 5, 4556-4567.

28 X. W. Jiang, Y. F. Liu, J. Liu, Y. L. Luo and Y. N. Lyu, RSC Adv., 2015, 5, 98508-98513.

29 Y. X. Li, Z. Y. Sun, T. T. Sun, L. Chen, Z. G. Xie, Y. B. Huang and X. B. Jing, RSC Adv., 2013, 3, 21302-21305.

30 Z. G. Xie, C. Wang, K. E. de Krafft and W. B. Lin, J. Am. Chem. Soc., 2011, 133, 2056-2059.

31 S. Das, P. Heasman, T. Ben and S. L. Qiu, Chem. Rev., 2017, 117, 1515-1563.

32 L. Segura, M. J. Mancheňo and F. Zamor, Chem. Soc. Rev., 2016, 45, 5635-5671.

33 Z. F. Pang, S. Q. Xu, T. Y. Zhou, R. R. Liang, T. G. Zhan and X. Zhao, J. Am. Chem. Soc., 2016, 138, 4710-4713. 
34 X. Chen, M. Addicoat, E. Q. Jin, H. Xu, T. Hayashi, F. Xu, N. Huang, S. Irle and D. L. Jiang, Sci. Rep., 2015, 5, 14650, DOI: $10.1038 /$ srep14650.

35 Y. F. Zeng, R. Y. Zou, Z. Luo, H. C. Zhang, X. Yao, X. Ma, R. Q. Zou and Y. L. Zhao, J. Am. Chem. Soc., 2015, 137, 1020-1023.

36 J. D. Vienna, Int. J. Appl. Glass Sci., 2010, 1, 309-321.

37 E. Kintisch, Science, 2005, 310, 1406.

38 D. F. Sava, M. A. Rodriguez, K. W. Chapman, P. J. Chupas, J. A. Greathouse, P. S. Crozier and T. M. Nenoff, J. Am. Chem. Soc., 2011, 133, 12398-12401.

39 R. C. Ewing and F. N. von Hippel, Science, 2009, 325, 151152.

40 H. Ma, J. J. Chen, L. X. Tan, J. H. Bu, Y. H. Zhu, B. E. Tan and C. Zhang, ACS Macro Lett., 2016, 5, 1039-1043.

41 S. U. Nandanwar, K. Coldsnow, A. Porter, P. Sabharwall, D. E. Aston, D. N. McIlroy and V. Utgikar, Chem. Eng. J., 2017, 320, 222-231.

42 X. Y. Zhang, P. Gu, X. Y. Li and G. H. Zhang, Chem. Eng. J., 2017, 322, 129-139.

43 K. W. Chapman, P. J. Chupas and T. M. Nenoff, J. Am. Chem. Soc., 2010, 132, 8897-8899.

44 D. F. Sava, M. A. Rodriguez, K. W. Chapman, P. J. Chupas, J. A. Greathouse, P. S. Crozier and T. M. Nenoff, J. Am. Chem. Soc., 2011, 133, 12398-12401.

45 Z. J. Yin, S. Q Xu, T. G. Zhan, Q. Yan Qi, Z. Q. Wu and X. Zhao, Chem. Commun., 2017, 53, 7266-7269.

46 H. Li, X. S. Ding and B. H. Han, Chem.-Eur. J., 2016, 22, 11863-11868.

47 Z. J. Yan, Y. Yuan, Y. Y. Tian, D. M. Zhang and G. S. Zhu, Angew. Chem., Int. Ed., 2015, 54, 12733-12737.

48 Y. F. Chen, H. X. Sun, R. X. Yang, T. T. Wang, C. J. Pei, Z. T. Xiang, Z. Q. Zhu, W. D. Liang, A. Li and W. Q. Deng, J. Mater. Chem. A, 2015, 3, 87-91.

49 W. Z. Guo, E. Galoppini, R. Gilardi, G. I. Rydja and Y. H. Chen, Cryst. Growth Des., 2001, 1, 231-237.

50 X. Qian, Z. Q. Zhu, H. X. Sun, F. Ren, P. Mu, W. D. Liang, L. H. Chen and A. Li, ACS Appl. Mater. Interfaces, 2016, 8, 21063-21069.

51 L. Stegbauer, K. Schwinghammer and B. V. Lotsch, Chem. Sci., 2014, 5, 2789-2793.
52 H. L. Nguyen, F. Gandara, H. Furukawa, T. L. H. Doan, K. E. Cordova and O. M. Yaghi, J. Am. Chem. Soc., 2016, 138, 4330-4333.

53 Y. X. Lin, X. F. Jiang, S. T. Kim, S. B. Alahakoon, X. S. Hou, Z. Y. Zhang, C. M. Thompson, R. A. Smaldone and C. F. Ke, J. Am. Chem. Soc., 2017, 139, 7172-7175.

54 Y. B. Wei, W. B. Chen, X. Y. Zhao, S. Y. Ding, S. Han and L. Chen, Polym. Chem., 2016, 7, 3983-3988.

55 C. He, Z. H. Lin, Z. He, C. Y. Duan, C. H. Xu, Z. M. Wang and C. H. Yan, Angew. Chem., Int. Ed., 2008, 47, 877-881.

56 S. M. S. V. Wardell, M. V. N. de Souza, J. L. Wardell, J. N. Low and C. Glidewell, Acta Crystallogr., Sect. A: Found. Adv., 2007, 63, 879-895.

57 Z. Toossi, J. Ellner and L. Friedman, Tuberculosis: Current Concepts and Treatment, CRC Press, Boca Raton, Florida, USA, 2001.

58 H. Qin, C. M. Wang, Q. Q. Dong, L. Zhang, X. Zhang, Z. Y. Ma and Q. R. Han, J. Magn. Magn. Mater., 2015, 381, 120-126.

59 C. Q. Kang, Z. Bian, Y. B. He, F. S. Han, X. P. Qiu and L. X. Gao, Chem. Commun., 2011, 47, 10746-10748.

60 D. F. Sava, T. J. Garino and T. M. Nenoff, Ind. Eng. Chem. Res., 2012, 51, 614-620.

61 T. Hasell, M. Schmidtmann and A. I. Cooper, J. Am. Chem. Soc., 2011, 133, 14920-14923.

62 Y. Z. Liao, J. Weber, B. M. Mills, Z. H. Ren and C. F. J. Faul, Macromolecules, 2016, 49, 6322-6333.

63 S. Lagergren, K. Sven. Vetenskapsakad. Handl., 1898, 24, 1-39.

64 Y. S. Ho, Ph. D. thesis, University of Birmingham, Birmingham, 1995.

65 C. Falaise, C. Volkringer, J. Facqueur, T. Bousquet, L. Gasnot and T. Loiseau, Chem. Commun., 2013, 49, 10320-10322.

66 I. Langmuir, J. Am. Chem. Soc., 1916, 38, 2221-2295.

67 T. W. Webi and R. K. Chakravort, AIChE J., 1974, 20, 228-238.

68 H. M. F. Freundlich, Z. Phys. Chem., 1906, 57, 385-471.

69 F. Tan, D. Sun, J. Gao, Q. Zhao, X. Wang, F. Teng, X. Quan and J. Chen, J. Hazard. Mater., 2013, 244, 750-757.

70 R. H. Petrucci, General Chemistry, Macmillan, New York, 5th edn, 1989.

71 M. A. A. Salam, M. A. Gabal and A. Y. Obaid, Synth. Met., 2012, 161, 2651-2658.

72 Y. Liu and Y. J. Liu, Sep. Purif. Technol., 2008, 61, 229-242. 